resolve with this approach than with the hit-and-miss methods that are usually adopted.

1 Department of Health and Social Security. Digest of health statistics. London: HMSO, 1971.

${ }^{2}$ Bridger RC. Sinusitis: an improved regime of investigation for the clinical laboratory. $\mathcal{F}$ Clin Pathol 1980;33:276-81.

${ }^{3}$ Lystad A, Berdal P, Lund-Iversen L. The bacterial flora of sinusitis with an in vitro study of the bacterial resistance to antibiotics. Acta Otolaryngol (Stockh) 1964;188, suppl:390-9.

4 Smith JM, Smith IM. The medical treatment of sinusitis. Otolaryngol Clin North Am 1971;4:39-55.

5 Dawes JDK. Chemotherapy in infections of the ear, nose and throat. Practitioner 1971 ;207:735-42.

- Sparrevohn UR, Buch A. The bacteriology of maxillary sinusitis. Acta Otolaryngol (Stockh) 1946;34:425-36.

${ }^{7}$ Frederick J, Braude AI. Anaerobic infection of the paranasal sinuses. N Engl f Med 1974;290:135-7.

\section{The risks of assessing risks}

No scientific or technological activity can be completely free from risk. If we want to be able to use electricity, take drugs when we are ill, and travel by car or plane then people are going to die and be injured as a result. Though risks cannot be totally eradicated, they can be measured, investigated, evaluated, controlled, and reduced; and these studies-and how the public perceives risks-were the subjects of a twoday conference at the Royal Society last week.

Why have scientists begun to measure risks? Probably because people's attitudes to misfortune have changed: fatalism has faded, and when a disaster occurs people now look for a cause and a scapegoat. As Dr P G Harvey of Imperial Chemical Industries said: "This is the first generation that feels it is entitled to immortality." Often the public have blamed industry and technology for misfortune; applied science and scientists themselves have become suspect; and, as Professor D Pearce of Aberdeen suggested, "risk analysis has appeared as a defence against these accusations."

Much of the conference was devoted to methods of measuring risk, which all agreed was extremely difficult. Ultimately, the magnitude of any misfortune was a subjective judgment. The social importance of an undesired event, the number of people affected, and the probability of it happening all had to be quantified. Was the death of an infant equivalent to the death of an 80-year-old? Was death by fire equivalent to death by lung cancer? Most speakers agreed that any analysis that treated all deaths as equivalent was worthless. Repeatedly the conference returned to this theme that the way the public viewed risks, which might be "irrational," was just as important as the way that experts measured them. Experts' and the public's assessments were seen as "different but complementary."

The second problem in measuring risks was that in almost all cases the data were limited and unreliable. Even mortality data related to social class and occupation, a risk measure familiar to most doctors, need to be intepreted with the greatest caution. Yet at least death was an easily defined event and there was a great deal of past experience to predict from. With many risk analyses there was no such past experience-the prime example being a core meltdown in a nuclear reactor. With new drugs, too, there were formidable problems in predicting and measuring risks. Increasingly refined toxicological studies in animals permitted better analyses, but unexpected side effects would always be seen when the drugs were first used in man. Even if they existed past data might be very sparse. Professor E D Acheson from Southampton explained that to predict the risk from an environmental carcinogen the dose-response curve and the exposure of individuals had to be known; yet for only four environmental carcinogens-cigarettes, alcohol, asbestos, and ionising radiation-was there enough information. "No human data are better than indifferent data," he dolefully concluded. A further problem with measuring risk was assessing the human factor. Men ignored instructions, dropped spanners into important works, and slept through alarms, and sometimes they would deliberately abuse and sabotage.

Once risks have been measured they must be evaluated. With this problem in mind several psychologists spoke at the conference. Undoubtedly a gap exists between the measurements of scientists and the perceptions of the public: evidence was presented that the public regard nuclear power as particularly risky while the experts regard it as relatively safe compared with other forms of energy production. The factors that affect subjective assessment of risk were subtle and complicated, but among those mentioned were whether a risk was voluntary; whether a hazard was familiar; whether the risk was to an individual or to a whole community; the cause of a hazard; and the size of a catastrophe. Several speakers pointed out that looking back on changes in legislation, large and spectacular catastrophes-for instance, Aberfan and Flixborough-have had a strong effect.

How could risk assessments be used? They can be used to reduce risks-industrial accidents are declining at a rate of about $5 \%$ a decade. Secondly, they permit intelligent choices between different technologies; this is, perhaps, most important in relation to energy production. Thirdly, regulatory bodies may soon begin to specify numerically what is an acceptable risk-but how they will decide what is acceptable remains problematical. Risk assessment, no matter how refined it became, can be only one tool in decision making.

\section{Alzheimer's disease}

Dementia is one of the greatest problems facing modern society, and yet one that seems little appreciated. The condition affects one person in every six over the age of $65 .{ }^{12}$ Those affected survive only one-third as long as healthy people of the same age and sex, but dementia greatly taxes the family and the medical and nursing professions-and, indeed, is a severe burden on the economy.

The most common cause of dementia is Alzheimer's disease. Postmortem examination of patients with dementia shows its characteristic features in half of all cases; multi-infarct dementia accounts for $20 \%$, and in a further $20 \%$ these two disorders are present together. ${ }^{3}$ Inherited metabolic abnormalities, chronic alcoholism, and other causes account for the remainder. Treatable causes of dementia such as normalpressure hydrocephalus, vitamin deficiencies, and metabolic disorders form a very small proportion of the total.

Alzheimer's disease may be readily diagnosed clinically in most cases, and the division into presenile and senile forms is no longer thought worth while. The typical patient preserves his personality in the early stages but shows an inability to learn new material and short-term memory loss. Many patients are also depressed. The diagnosis is confirmed histologically by the presence of senile plaques, neurofibrillary \title{
.
}

